Review

\title{
MicroRNAs Regulate Mitochondrial Function in Cerebral Ischemia-Reperfusion Injury
}

\section{Yue Hu ${ }^{1, \dagger}$, Hao Deng ${ }^{2, \dagger}$, Shixin $\mathrm{Xu}{ }^{2, *}$ and Junping Zhang ${ }^{2, *}$}

1 Graduate School, Tianjin University of Traditional Chinese Medicine, 312 An Shan Xi Road, Nan Kai District, Tianjin 300193, China; E-Mail: tingqianliu90@sina.com

2 Medical Experiment Center, First Teaching Hospital of Tianjin University of Traditional Chinese Medicine, 314 An Shan Xi Road, Nan Kai District, Tianjin 300193, China; E-Mail: LJdenghao@yahoo.com

$\dagger$ These authors contributed equally to this work.

* Authors to whom correspondence should be addressed; E-Mails: shixinxu1973@outlook.com (S.X.); Zhtcm@hotmail.com (J.Z.); Tel./Fax: +86-22-2798-7795 (S.X.); +86-22-2743-2016 (J.Z.).

Academic Editor: Y-h. Taguchi

Received: 16 August 2015 / Accepted: 8 October 2015 / Published: 20 October 2015

\begin{abstract}
Cerebral ischemia-reperfusion injury involves multiple independently fatal terminal pathways in the mitochondria. These pathways include the reactive oxygen species (ROS) generation caused by changes in mitochondrial membrane potential and calcium overload, resulting in apoptosis via cytochrome c (Cyt c) release. In addition, numerous microRNAs are associated with the overall process. In this review, we first briefly summarize the mitochondrial changes in cerebral ischemia-reperfusion and then describe the possible molecular mechanism of miRNA-regulated mitochondrial function, which likely includes oxidative stress and energy metabolism, as well as apoptosis. On the basis of the preceding analysis, we conclude that studies of microRNAs that regulate mitochondrial function will expedite the development of treatments for cerebral ischemia-reperfusion injury.
\end{abstract}

Keywords: ischemic-reperfusion; mitochondria; miRNAs; cerebral 


\section{Introduction}

With substantial incidence, prevalence, and mortality [1], stroke is the second leading cause of death worldwide [2]. Ischemic strokes are caused by cerebral thrombosis or embolism within a blood vessel. As a result, local brain tissue become necrotic and apoptotic often leading to corresponding neurological deficits. One of the most effective strategies to treat this disease is immediate restoration of blood flow to the brain, although it imposes risks of further cellular necrosis and neural damage $[3,4]$. This damage mainly involves free radical generation, intracellular calcium overload, energy metabolism dysfunction, and apoptosis [5-11].

Mitochondria maintain homeostasis through energy production, synthesis of many compounds, and participation in cell signaling networks [12]. Detailed observations of the mechanisms of ischemia-reperfusion injury are difficult to conduct in the intact brain; however, cerebral ischemia may directly cause mitochondrial dysfunctions because the brain is highly susceptible to ischemic hypoxia [13]. The responses of mitochondria to cerebral ischemic-reperfusion injury are not yet completely identified, although several studies have suggested that during ischemic-reperfusion, mitochondria overproduce ROS that consume antioxidants, suppress the endogenous antioxidative defense system, disturb energy metabolism, and cause neuronal apoptosis [14-16].

Emerging evidence suggests that micro-RNAs (miRNAs) are associated and localized to mitochondria, indicating that the intricacy of the regulation of mitochondrial function is mediated by proteins which encoded by the nuclear and mitochondrial genomes [17-19]. Because mitochondria contain proteins mainly encoded by the nuclear genome [20], they may serve as a potential site for miRNA-mediated posttranscriptional regulation [21,22]. For instance, miRNAs that regulate mitochondrial function at the posttranscriptional level affect mitochondrial homeostasis, energy metabolism, oxidative stress, and apoptosis under physiological and pathological conditions [17,23,24].

The pathogenesis of cerebral ischemia-reperfusion injury involves miRNAs that alter the mitochondrial response and regulate the expression of key elements that mediate neuronal survival and apoptosis [25-28], including changes in mitochondrial membrane potential, ROS generation under oxidative stress, and apoptosis induced by energy metabolism. In this review, we briefly summarize the molecular mechanisms that determine mitochondrial function and the roles of miRNAs during ischemia-reperfusion.

\section{Mitochondria in Ischemia-Reperfusion Injury}

Mitochondria are found in almost all eukaryotic cells and function as "power houses" [29]. The mitochondrial matrix is surrounded by a permeable outer membrane and a much less permeable inner membrane. The outer membrane is freely permeable to small metabolites due to the presence of an abundant protein, and the inner membrane includes components of the respiratory chain that catalyzes oxidative phosphorylation (OxPhos). Mitochondria are the main organelles that generate adenosine triphosphate (ATP) [30] and serve as the major sites of the oxidative metabolism of carbohydrates, fats, amino acids, and other biological molecules [31,32]. Mitochondria represent a key role in the pathogenesis of cerebral ischemia-reperfusion injury, which involves ROS generation, dysfunctional energy metabolism, and mitochondria-induced apoptosis. 


\subsection{Generation of ROS}

Mitochondria are potential major intracellular sources of ROS in almost all cells. The electron transport chain localized to the mitochondrial inner membrane is the main site for ROS generation [33]. Specifically, mitochondrial components such as the growth factor adaptor Shc, NADPH oxidase-4 (NOX4), and the mitochondrial redox carriers complexes I and III [34] promote production of ROS [35-40]. Under normal physiological conditions, xanthine oxidase, and the electron transport chain of the mitochondrion, arachidonic acid, and NADPH oxidase are involved in the generation of the sources of ROS, for instance, superoxide anion $\left(\cdot \mathrm{O}_{2}{ }^{-}\right)$, hydrogen peroxide $\left(\mathrm{H}_{2} \mathrm{O}_{2}\right)$, and hydroxide radical $\left(\cdot \mathrm{OH}^{-}\right)$[31]. Further, a series of intracellular antioxidants, for instance, superoxide dismutase (SOD), glutathione peroxidase (GSHPx), and glutathione rapidly remove excess ROS [41]. ROS remains at low levels under physiological conditions, and the homeostasis of cellular redox is crucial for numerous biological processes [42,43]. During brain ischemia-reperfusion, several processes, including the initial change in mitochondrial membrane potential and calcium overload, occur concurrently and cause neurons to undergo apoptosis. Among these processes, oxidative stress caused by excess ROS generation plays a major role in brain damage $[44,45]$.

Sanderson et al. (2013) considered that mitochondrial changes during brain ischemia-reperfusion injury involve the following steps: ischemic starvation, reperfusion-induced hyperactivation, mitochondrial dysfunction, and delayed neuronal death [46]. During oxidation associated with mitochondrial respiration, energy is produced by the electrochemical potential stored in the inner mitochondrial membrane, which causes an asymmetric distribution of protons and other ions with different concentrations on both sides of the mitochondrial membrane that generates the mitochondrial membrane potential $(\Delta \Psi \mathrm{m})$. The $\Delta \Psi \mathrm{m}$ is considered a reliable indicator of mitochondrial membrane permeability and a sensitive indicator of mitochondrial function [47].

Furthermore, intracellular $\mathrm{Ca}^{2+}$ maintains homeostasis through its uptake and release via the mitochondrial calcium uniporter [48,49], mitochondrial $\mathrm{Na}^{+} / \mathrm{Ca}^{2+}$ exchanger, mitochondrial permeability transition pore (MPTP), and pathways including the $\mathrm{Na}^{+}$-independent pathway of $\mathrm{Ca}^{2+}$ efflux and $\mathrm{H}^{+} / \mathrm{Ca}^{2+}$ antiporter pathway, etc. [50]. Under physiological conditions, $\Delta \Psi \mathrm{m}$ is negative in the inner chamber; by contrast, it is positive in the outer chamber; only a small number of electrons "leak" in complexes I and III [42]. During ischemia, the initial change in mitochondria involves their membrane potential, and ROS generation is partly dependent on this change [39]. Insufficient oxygen delivery during ischemia causes increased electron leakage mediated by complexes I and III and triggers the disruption of ion pump function. Consequently, intracellular $\mathrm{Ca}^{2+}$ overload is detected, the sustained opening of the MPTP is stimulated [51], and the collapse of the electrochemical potential of $\mathrm{H}^{+}$is triggered, all of which inhibits ROS production. When blood supply is reestablished, as it occurs due to membrane instability during early reperfusion, the reintroduction of oxygen enhances electron leakage, which markedly increases ROS production (called the ROS “burst”) [46]. $\mathrm{Ca}^{2+}$ inhibits complex I, which increases ROS generation in vitro and in vivo [52]. 


\subsection{Energy Metabolism}

Mitochondria generate ATP for most cells through oxidative phosphorylation to produce more than 95\% of a cell's energy under physiological conditions via complexes I-V [53]. In almost all animal models of stroke, the oxidative metabolism in the ischemic core of brain is impaired by glucose and oxygen deficiency, which rapidly alters ATP and other energy-related metabolites that are mainly involved with the mitochondria [54]. In the mitochondrial matrix, the pyruvate oxidation, fatty acid (FA) oxidation, glutamine metabolism, and tricarboxylic acid (TCA) cycle pathways are associated with energy metabolism [32]. In cerebral ischemia-reperfusion injury, energy metabolism in the mitochondria may change through various mechanisms.

Under pathological conditions, most cells in the penumbra remain viable after $2 \mathrm{~h}$ of ischemia; however, glucose and ATP contents decrease considerably and the phosphocreatine content decreases to approximately $70 \%$ of non-ischemic values [55]. A portion of the adenosine diphosphate (ADP) generated through ATP hydrolysis is metabolized to adenosine monophosphate and ATP. Ischemia inhibits oxidative metabolism. In contrast, anaerobic glycolysis increases indirectly and produces large amounts of lactic acid that decrease intracellular $\mathrm{pH}$, causing a decrease in or loss of activities of multiple intracellular enzymes [56]. Moreover, the decrease in glucose metabolism may cause increased pyruvate oxidation [57], affecting the activation of acetyl coenzyme A and causes persistent activation of the TCA cycle [58]. Reperfusion partially restores blood flow in the brain and the glucose utilization is decreased to approximately half of the normal range in the ischemic core $[59,60]$. It also causes the concentration of ATP to recover more slowly than that of phosphocreatine or the adenylate energy charge. However, neurons in the penumbral tissue undergo entire or nearly entire recovery of phosphocreatine. The adenine nucleotide balance shows that the penumbra region of energy metabolism is moderately affected [60].

\subsection{Release of Cyt $\mathrm{c}$}

Cyt c, which plays a major role in apoptosis, is located in the inner membrane of mitochondria, is the first proapoptotic protein discovered in the mitochondria [61]. Its function is required for OxPhos and is implicated in intrinsic type II apoptosis [62]. MPTP likely promotes apoptosis caused by Cyt c release, then activates caspases (see below) $[51,63,64]$. The release of Cyt $\mathrm{c}$ from the mitochondria into the cytoplasm is the main inducer of apoptosis [65]. The mechanisms of mitochondrial apoptosis are as follows: First, loosely coupled or tightly bound Cyt $\mathrm{c}$ is damaged in the mitochondrial membrane and then released. Second, Bax (see below) in the outer mitochondrial membrane increases the permeability of the outer membrane of mitochondria and stimulates the release of free Cyt c [66].

The Bcl-2 family and its regulation of mitochondrial permeability were the focus of extensive investigations. The members of the Bcl-2 family can be categorized according to their specific functions during apoptosis [67] as follows: (1) anti-apoptotic proteins, for instance, Bcl-2, Bcl-xl, and Bcl-W, which contain a minimum of three $\mathrm{BH}$ domains; and (2) proapoptotic proteins such as Bax, and Bak, which contain domains of $\mathrm{BH} 1, \mathrm{BH} 2$, and $\mathrm{BH} 3$. BH3-only proteins, which include Bid, Bad, and NOXA, are another group of pro-apoptotic proteins [68-70]. Bcl-2 family proteins contain 20 amino acid residues in the hydrophobic region in the C-terminal region that mediates interaction with the outer mitochondrial membrane. This region is present on the mitochondrial membrane and regulates the 
release of Cyt c. Anti-apoptotic Bcl-2 proteins, which are distributed mainly in the outer mitochondrial membrane, nuclear membrane, and endoplasmic reticulum (ER), elicit a stable organelle membrane effect. Unlike anti-apoptotic proteins, Bax and Bak directly interact with mitochondria, resulting in the release of Cyt $\mathrm{c}$ to trigger apoptosis $[71,72]$.

The mitochondria involved in brain ischemia-reperfusion injury trigger apoptosis [72]. The production of ROS and release of apoptotic factors into the cytoplasm are implicated in the activation of cell death cascades. These factors mainly includes Cyt c and Apoptosis-inducing factor (AIF) [73]. Cyt $\mathrm{c}$ is transported through specific pores formed by proapoptotic proteins such as Bax, which are embedded in the outer mitochondrial membrane. During ischemia-reperfusion, the sequence of apoptotic events begins with the binding of Cyt $\mathrm{c}$ to apoptosis protein-associated factor 1 (Apaf-1) [74,75]. The Apaf-1/caspase-9/Cyt c complex is formed, and caspase-3 is activated, which triggers neuronal death [76].

\section{3. miRNAs Regulate Mitochondrial Function during Cerebral Ischemia-Reperfusion Injury}

miRNAs (20-22 nucleotides) regulate the expression of genes by binding to the $3^{\prime}$ untranslated regions of mRNAs, causing downregulation of gene expression or mRNA degradation [77,78]. The biogenesis of all miRNA families converts the primary (pri)-miRNA transcript into the active mature miRNA. The pri-miRNA transcript is cleaved by the enzyme Drosha, yielding the precursor (pre)-miRNA [79]. In the cytoplasm, pre-miRNAs are converted into 18-22 bp double-stranded RNAs [80]. After Dicer cleavage, the mature miRNA is passed into the RNA-induced silencing complex, where it guides the complex to target mRNAs [81]. Generally, passive-strand miRNA (miRNA*) is degraded and does not affect gene expression. However, recent research indicated that miRNA* molecules have similar biological effects as mature miRNAs by repressing target mRNAs [82]. Since the discovery of lin-4 and let-7, numerous miRNAs were detected using techniques such as northern blotting, deep sequencing, and bioinformatics [83-85]. Evidence indicates that miRNAs are essential for cellular processes such as proliferation, differentiation, and apoptosis [86-88].

The expression of more than $30 \%$ of genes for coding proteins are regulated by miRNAs [89]. Moreover, cerebral miRNAs are altered after ischemia-reperfusion injury, suggesting that miRNA-mediated translational may play a pivotal role in modulating gene expression $[28,90]$. Because the mitochondrial outer membrane is freely permeable to small metabolites, it is the main location for assembling miRNA and its processing components. miRNAs may also translocate to the mitochondrial matrix to perform their function by targeting mitochondrial genomes. Mitochondrion-associated miRNAs participate in cellular processes such as response to stress, metabolism, and death. Therefore, mitochondrial function during cerebral ischemia-reperfusion injury requires highly coordinated gene expression, which is partly modulated by numerous miRNAs. 


\subsection{Mitochondrial Oxidative Stress}

miRNAs have been detected within or in association with mitochondria from various tissues and cell types involved in a variety of biological processes [91-93]. These miRNAs function as critical regulatory molecules in the regulation of cellular redox reactions. Therefore, we assumed that these molecules act as regulators during cerebral ischemia-reperfusion injury (Table 1, lines 1 to 14). During early ischemia, the mitochondrial membrane potential changes due to hypoxia. For instance, miR-210 is stimulated by HIF-1 $\alpha$-regulated hypoxia and miR-210 is strongly induced in response to hypoxia, thereby activating ROS generation [94] (Figure 1). During reperfusion, there is a burst of ROS, including ${ }^{\cdot} \mathrm{O}_{2}{ }^{-}, \mathrm{H}_{2} \mathrm{O}_{2}$, and $\cdot \mathrm{OH}^{-}$. Moreover, miRNAs regulate ROS generation to a certain extent under conditions of mitochondrial oxidative stress. $\mathrm{H}_{2} \mathrm{O}_{2}$-induced upregulation of $\mathrm{MDH}$ is likely mediated by the downregulation of miR-743a [95]. miR-128a directly target Bim-1 to increase intracellular ROS levels and then alters the intracellular redox state [96]. miR-145 represses CaMKII- $\delta$ expression and ROS-induced $\mathrm{Ca}^{2+}$ overload [97]. Similarly, miR-155 represses the expression of src homology 2 (SH2)-containing inositol 5-phosphatase 1 (SHIP1) and increases ROS generation [98].

miRNAs influence the balance of ROS. For instance, NOX4 and NOX2 belong to the NOX family of NADPH oxidases that produce large amounts of ROS [99]. NOX4 was discovered in nonphagocytic cell types and tissues, and its mRNA is the direct target of miR-23b [100] (Figure 1). miRNA-25 increases the expression of NOX4 and mediates oxidative/nitrative stress as well as the consequent mitochondrial dysfunctions [101]. NOX2 increases ROS generation in various cell types, and NOX2 mRNA is the target of miR-34a, which exhibits proapoptotic activity, mainly by enhancing NOX2 expression and ROS production [102]. In addition, the ROS defense system is composed of several enzymes, including SOD, catalases (CATs), GSHPx, and PRDXs [103].

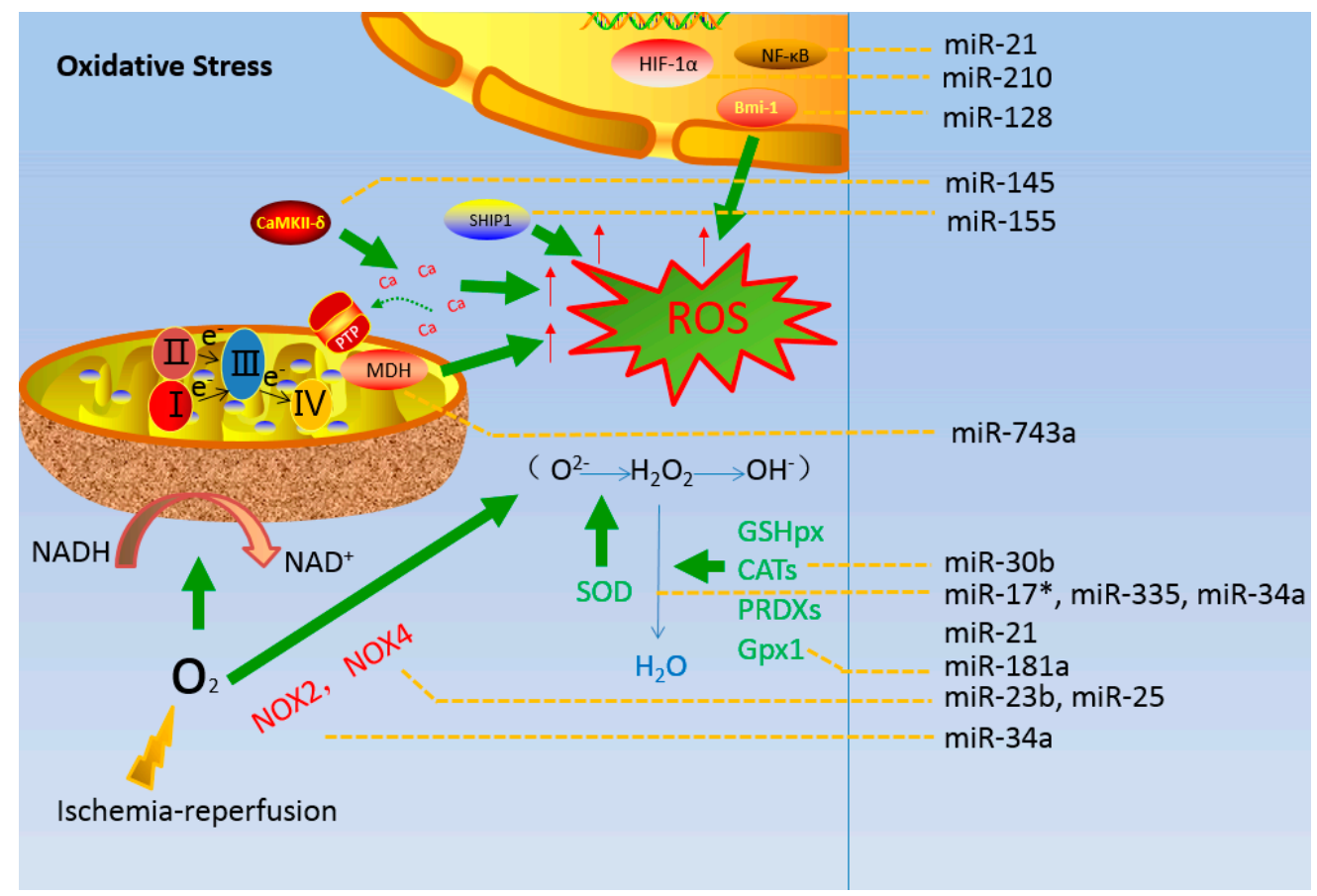

Figure 1. Regulatory role of miRNAs in mitochondrial oxidative stress during brain ischemia-reperfusion injury. 
Under conditions of pathological reperfusion, three antioxidant enzymes, MnSOD, GPX2, and Txnrd2, present in mitochondria, are negatively regulated by miR-17* [104]. Moreover, the senescence of cells is inhibited by miR-335 and miR-34a through the upregulation of SOD2 and Txnrd2 expression [105] (Figure 1), causing a decrease in ROS production. Inhibition of miR-181a expression protects cells against oxidative stress-induced apoptosis through the direct inhibition of Gpx1 expression and ROS generation [106]. These antioxidant enzymes, which are the major components of the primary antioxidant system, coordinately remove the ROS generated in the mitochondria. Nevertheless, the conversion of ${ }^{-} \mathrm{O}_{2}^{-}$to $\mathrm{H}_{2} \mathrm{O}_{2}$ is inhibited by miR-21, which occurs when miR-21 directly decreases SOD3 levels or indirectly reduces SOD2 levels, and ROS levels are affected by miR-21 [107]. Furthermore, NF- $\mathrm{kB}$ increases miR-21 expression under oxidative stress; however, $\mathrm{H}_{2} \mathrm{O}_{2}$-induced ROS activity is partly protected by the overexpression of miR-21 [108]. ROS is similarly regulated by miR-30b that targets CATs, and antisense molecules enhance cytoprotective mechanisms against oxidative stress by strengthening the antioxidant defense system [109].

Excessive amounts of ROS including $\mathrm{O}_{2}^{-}, \mathrm{H}_{2} \mathrm{O}_{2}$, and hydroxyl radicals $(\mathrm{OH} \cdot)$, are produced in the mitochondria during brain ischemia-reperfusion injury. The nuclear transcription factors HIF-1 $\alpha$ and NF- $\kappa \mathrm{B}$ contribute to the generation of ROS during cerebral ischemia-reperfusion. SOD detoxifies $\mathrm{O}_{2}{ }^{-}$by converting it to $\mathrm{H}_{2} \mathrm{O}_{2}$, which is converted to $\mathrm{H}_{2} \mathrm{O}$ by CATs or GSHPx/Gpx1. NOX4 and NOX2 generate $\mathrm{O}_{2}{ }^{-}$-generating enzymes. miRNAs targeting mitochondrial-related proteins and antioxidative enzymes as well as nuclear transcription factors under mitochondrial oxidative stress are shown in Figure 1.

Table 1. miRNAs associated with mitochondrial oxidative stress, energy metabolism and apoptosis.

\begin{tabular}{cccc}
\hline miRNAs & Target & Function & References \\
\hline miR-181a & GPx1 & reduces ROS production & {$[106]$} \\
miR-210 & ISCU, COX10 & activates the generation of ROS & {$[94]$} \\
miR-21 & SOD3, TNF- $\alpha$ & modulates the levels of ROS & {$[107]$} \\
miR-743a & mdh2 & increase MDH production & {$[95]$} \\
miR-145 & CaMKII & regulates ROS-induced Ca ${ }^{2+}$ overload & {$[97]$} \\
miR-155 & SHIP1 & enhances ROS production & {$[98]$} \\
miR-23b & NOX4 & increases the level of ROS scavengers & {$[110]$} \\
miR-25 & NOX4 & mediates oxidative/nitrative stress & {$[101]$} \\
miR-34a & NOX2 & enhanced ROS production & {$[102]$} \\
miR-30b & CATs & againsts oxidative stress & {$[109]$} \\
miR-17* & MnSOD, GPX2, TrxR2 & clears up the high levers of ROS & {$[104]$} \\
miR-335, miR-34a & SOD2, Txnrd2 & decrease generation of ROS & {$[105]$} \\
miR-128 & Bmi-1 & increases Intracellular ROS levels & {$[96]$} \\
miR-302 & E2F3 & reduces intracellular ROS & {$[111]$} \\
miR-210 & ISCU, COX10 & up-regulates the glycolysis & {$[94]$} \\
miR-23a/b & c-Myc & enhances glutamine metabolism & {$[112]$} \\
miR-378/378* & PGC-1 $\beta$ & energy metabolism & {$[113]$} \\
miR-378* & PGC-1 $\beta$ & inhibits TCA gene expression & {$[114]$} \\
miR-15a & UCP-2 & inhibits the synthesis of insulin & {$[115]$} \\
miR-15b & Arl2 & decrease mitochondrial integrity & {$[116]$} \\
\hline
\end{tabular}


Table 1. Cont.

\begin{tabular}{cccc}
\hline miRNAs & Target & Function & References \\
\hline miR-338 & COXIV & decreases oxidative phosphorylation & {$[117]$} \\
miR-141 & S1C25A3 & influences mitochondrial ATP production & {$[118]$} \\
miR-199a-5p & CAV1 & inhibits ATP levels, mitochondrial DNA & {$[119]$} \\
miR-696 & PGC-1a & up-regulates aerobic metabolism & {$[120]$} \\
miR-122 & PKM2 & increases glycolysis & {$[121]$} \\
miR-221/222 & PUMA & inhibits mitochondrial pathway of apoptosis & {$[122]$} \\
miR-155 & p53 & accumulates DNA damage & {$[98]$} \\
miR-134 & Bcl-2 & anti-apoptotic gene Bcl-2 & {$[123]$} \\
miR-29a & BH3-only & reduces neuronal vulnerability & {$[124]$} \\
miR-145 & BH3-only & against mitochondria apoptotic pathway & {$[125]$} \\
miR-30a & LC3 & enhances beclin 1-mediated autophagy & {$[126]$} \\
miR-181a & GRP78 & regulates GRP78 expression & {$[127]$} \\
miR-497/302b & Bcl-2 & induces neuronal apoptosis & {$[128]$} \\
miR-21 & Bcl-2 & decreases Bax/Bcl-2 ratio & {$[129]$} \\
miR-29c & Birc2, Bak1 & increases apoptosis & {$[130]$} \\
miR-23a & XIAP & leads to different ways of cell death & {$[131]$} \\
miR-23a & APAF-1/caspase-9 & increases in the activation of caspase-9 & {$[132]$} \\
miR-499 & Drp1 & regulates mitochondrial dynamics & {$[133]$} \\
miR-133 & caspase-9, -3 & increases caspases-9 and -3 & {$[134]$} \\
miR-124 & Ku70 & against I/R-induced neuronal death & {$[135]$} \\
miR-761 & MFF & inhibits mitochondrial fission and apoptosis & {$[136]$} \\
miR-214 & NCX1 & against Ca ${ }^{2+}$ overload injury and cell death & {$[137]$} \\
\hline
\end{tabular}

\subsection{Energy Metabolism in Mitochondria}

Mitochondrial energy metabolism during brain ischemia-reperfusion injury is regulated by miRNAs [138]. (Table 1, lines 15 to 25). During the early stages of ischemia, oxidative metabolism declines as glycolysis increases, and studies of miR-210 under hypoxia in different cell types show that the main components of hypoxic response are regulated by HIF-1 $\alpha$ [139]. HIF-1 $\alpha$ contributes to the metabolic shift by downregulating several steps of mitochondrial metabolism through direct inhibition of the Fe-S cluster assembly protein 1/2 and Cyt c oxidase 10 (COX10) expression, which decreases mitochondrial function and upregulates glycolysis [94] (Figure 2).

During hypoxia, glucose, ATP, and phosphocreatine levels are reduced, and miRNAs regulate ATP generation and conversion to ADP. For instance, miR-15b modulates the concentration of ATP by targeting Arl2, and miR-15b overexpression reduces Arl2 expression, and therefore inhibits ADP/ATP exchange and ATP synthesis [116]. Furthermore, miR-15a directly inhibits the expression of the gene encoding uncoupling protein-2 (UCP-2) to increase oxygen consumption and reduce ATP generation [115]. COXIV, a key protein in the electron transfer chain of the mitochondria, takes part in ATP production. The changes of COXIV levels affects mitochondrial function. Moreover, miR-338 regulates the expression of COXIV and targets a wide variety of mitochondrial mRNAs that encode vital proteins are involved in oxidative phosphorylation [117]. 


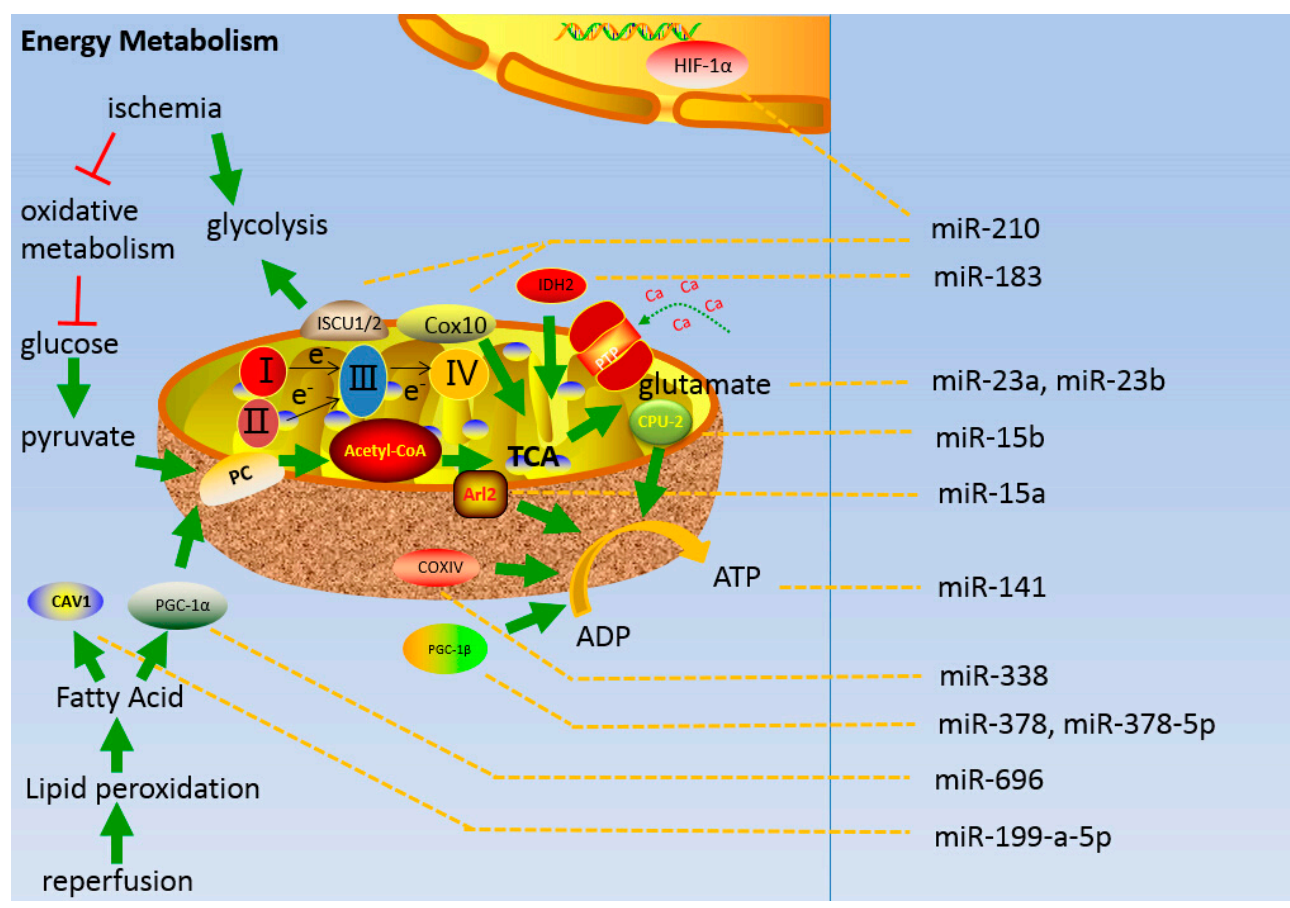

Figure 2. Energy metabolism in the mitochondria during cerebral ischemia-reperfusion injury and the regulatory role of miRNAs.

miR-378 inhibits PGC-1 $\beta$ expression [113], whereas miR-378-5p activates PGC-1 $\beta$ expression and induces reduction in tricarboxylic acid cycle gene expression [114] (Figure 2). Numerous miRNAs function during reperfusion which involves in lipid peroxidation and excess lactate production with excessive ROS generation and synthesis of glutathione from glutamate [140]; the following are the examples: miR-23a/b represses glutaminase expression [112], miR199-a-5p participates in mitochondrial activity and mitochondrial $\beta$-oxidation. miR-199-a-5p overexpression exacerbates the deposition of FA and decreases ATP and mitochondrial DNA (mtDNA) concentrations by inhibiting caveolin1 [119]. miR-696 directly targets the activated receptor gamma co-activator $1-\alpha$ (PGC-1 $\alpha)$ and regulates FA oxidation capacity and mitochondrial biogenesis. Overexpression of miR-696 decreases FA oxidation and mtDNA content [120]. miR-141 regulates SLC25A3 expression, and affects mitochondrial ATP production [118]. The overexpression of miR-183 inhibits the expression of IDH2, which is one of the mitochondrial enzymes related to the TCA cycle [141].

During cerebral ischemia, oxidative metabolism and glucose content decrease considerably, but glycolysis is sustained, causing impaired oxidative metabolism of pyruvate by mitochondria. The process of generating energy by glucose oxidative metabolism mainly includes the generation of pyruvate, pyruvate metabolism, and TCA cycle. Lipid peroxidation occurs during reperfusion. The miRNAs involved in this process are indicated on the right.

\subsection{Mitochondrial Pathways of Apoptosis}

Mitochondria-induced neuronal apoptosis during ischemia-reperfusion involves reduction of the mitochondrial membrane potential and opening of the MPTP that is associated with Bcl-2 family proteins [142]. Cyt c, AIF, and other apoptotic factors are released into the cytoplasm, as a result, Apaf-1 is activated, the caspase cascade is stimulated, and cell apoptosis is directly induced $[143,144]$. 
miRNAs involved in the mitochondrial apoptosis pathway regulate various proteins (Table 1 lines 26 to 42). For instance, p53 regulates the cell cycle and apoptosis, and p53 is activated in a microglia subpopulation in the inflamed human brain, causing cell death triggered via the mitochondrial apoptosis pathway [145,146] (Figure 3). p53 negatively regulates c-Maf in microglia by inducing miR-155 [147]. However, p53 activation and pernicious cascade resulting in the mitochondrial apoptotic pathway are limited by miR-30a [148].

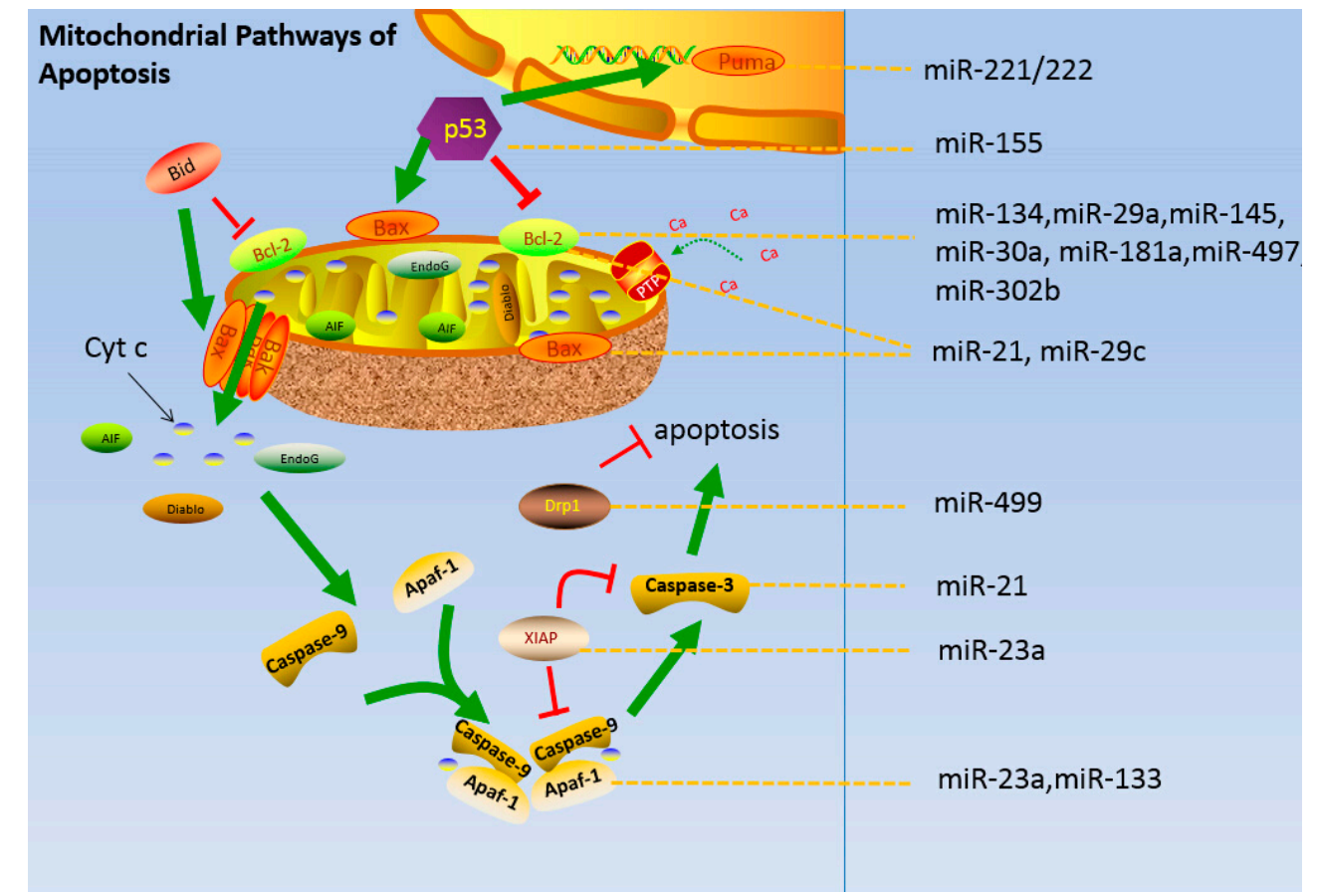

Figure 3. Apoptosis under pathological conditions of reperfusion and the regulatory roles of miRNAs.

The mitochondrial apoptotic pathway is inhibited by miR-221/222 through the regulation of the BH3-only protein PUMA [122]. Bnip3, a member of the BH3-only protein family, is a direct target of miR-145 and regulates the mitochondrial apoptotic pathway during myocardial ischemia-reperfusion injury [125]. miR-29a is highly expressed in astrocytes, and it targets PUMA to decrease ischemic injuries in vitro and in vivo and reduces ischemic brain injury by attenuating neuronal vulnerability [124]. Moreover, miR-29a targets multiple Bcl-2 family members, including those that are proapoptotic or anti-apoptotic, to regulate cell proliferation $[149,150]$. miR-181 levels change in response to stroke; in addition, increased GRP78 levels are implicated in cellular functions such as protein folding in the ER and inhibiting apoptosis [127] and in increasing the expression of Bcl-2 family members. Furthermore, global cerebral ischemia and focal ischemia are alleviated by inhibiting miR-181a production [151].

Moreover, Bcl-2 is a target of miR-134, miR-497, and miR-302 [123,128,152]. The overexpression of either miR-497 or miR-302b reduces the expression of their target genes and increases caspase-3-mediated apoptosis [128]. The downregulation of miR-134 reduces ischemic injury by enhancing the expression of CREB [123] (Figure 3). Moreover, miRNAs strongly regulate the downstream steps in the mitochondrial apoptotic pathway, and antisense miR-23a enhances apoptosis via the APAF-1/caspase-9 apoptotic pathway [132]. The X-linked inhibitor of apoptosis (XIAP), which 
is the main endogenous caspase inhibitor, is the target of miR-23a. After a stroke, miR-23a expression in men and women differ significantly, leading to caspase-dependent and -independent cell deaths in women and men, respectively [131]. miR-133 increases caspase- 9 and caspase-3, thereby stimulating the mitochondrial apoptotic pathway [134] and miR-21-induces decreases in the Bax-to-Bcl-2 ratio and caspase-3 activity [129]. miRNA-29c directly targets the mRNAs encoding Birc2 and Bak1 and increases apoptosis [130]. Mitochondrial fission occurs through phosphorylation and dephosphorylation of dynamin-related protein 1 [153], which is regulated by miR-499 [133].

Cerebral ischemia-reperfusion injury triggers the mitochondrial release of Cyt c, AIF, Diablo, and EndoG via Bak. Cyt $\mathrm{c}$ then binds to procaspase-9 and Apaf-1 to form the apoptosome. The procaspase-9 complex is transactivated to activate caspase-9. Caspase- 9 cleaves and activates downstream caspases such as caspase- 3 to induce apoptosis. XIAP simultaneously inhibits caspases- 9 and caspase-3. Bcl-2 and Bax prevent Cyt c release and interfere with this pathway. p53 and PUMA are involved in this process. miRNAs that target the mitochondrial apoptotic pathways are indicated on the right in Figure 3.

\section{Perspectives}

Stroke is a multi-factor disease, with limited therapeutic strategies. Therefore, numerous clinical trials to treat this disease have failed [154]. The early stage of cerebral ischemia is accompanied by hypoxia, and mitochondria are the most sensitive organelles to hypoxia. During cerebral reperfusion, changes in mitochondria may partly predict disease progression. The levels of some miRNAs change significantly in cerebral ischemia-reperfusion injury $[155,156]$. In addition, miRNAs target various mitochondrial and mitochondria-associated proteins. Therefore, miRNAs may serve as useful tools to manipulate mitochondrial function (Table 1). The pathological process of the ischemia-reperfusion cascade in the brain involves a complex series of events, which may be driven by multiple cellular pathways that act coordinately, and miRNAs simultaneously regulate numerous target genes [157]. Therefore, miRNAs are potential targets for the treatment of stroke (Table 2). Moreover, products of one miRNA target genes may belong to the same functional protein-protein interaction network [158]. miRNAs may perform a range of functions, including regulation of long noncoding RNAs [159] and control of epigenetic mechanisms [160]. Current research indicates that the mechanisms of miRNA-targeting therapeutics include the following: (1) change in the absorption, distribution, metabolism, and excretion of anti-miRNAs; (2) upregulate the expression of targeted miRNAs or enhance their biogenesis; and (3) upregulate other miRNAs that target the same genes [161]. Most miRNA-targeting molecules of stroke are in the preclinical stage, and certain obstacles to their use must be removed. Although the multiplicity of binding targets presents potential difficulties, the modulation of miRNA levels may provide a new strategy for treating stroke and represents a potentially effective treatment paradigm. 
Table 2. miRNAs as therapeutic targets.

\begin{tabular}{cclcc}
\hline miRNAs & Indications & Method & Developmental Stage & References \\
\hline miR-181 & cerebral ischemia & antagomir therapy & preclinical & {$[127]$} \\
miR-181 & cerebral ischemia & antagomir therapy & preclinical & {$[162]$} \\
miR-181b & ischemic stroke & antagomir therapy & preclinical & {$[163]$} \\
miR-497 & ischemic brain injury & antagomir therapy & preclinical & {$[152]$} \\
Let7f & ischemic stroke & antagomir therapy & preclinical & {$[164]$} \\
miR-424 & cerebral I/R & antagomir therapy & preclinical & {$[165]$} \\
miR-200c & cerebral ischemia & antagomir therapy & preclinical & {$[166]$} \\
\hline
\end{tabular}

\section{Acknowledgments}

This work was supported by the State Natural Science Foundation of China (No. 81373850) and Tianjin Natural Science Foundation (No. 13JCZDJC31500).

\section{Author Contributions}

Yue Hu and Hao Deng wrote the paper and drafted the figures; Shixin Xu and Junping Zhang provided significant contribution to the revision of the manuscript.

\section{Conflicts of Interest}

The authors declare no conflict of interest.

\section{Abbreviations}

ATP: adenosine triphosphate; Apaf-1: apoptosis protein-associated factor 1; Cyt c: cytochrome c; Drp1: dynam-in-related protein 1; ER: endoplasmic reticulum; FA: fatty acid; MCU: mitochondrial calcium uniporter; miRNA: microRNA; MPTP: mitochondrial permeability transition pore; Nox4: NADPH oxidase-4; OxPhos: oxidative phosphorylation; ROS: reactive oxygen species; TCA: tricarboxylic acid; UCP-2: uncoupling protein-2; $\triangle \Psi \mathrm{m}$ : mitochondrial membrane potential.

\section{References}

1. Feigin, V.L.; Forouzanfar, M.H.; Krishnamurthi, R.; Mensah, G.A.; Connor, M.; Bennett, D.A.; Moran, A.E.; Sacco, R.L.; Anderson, L.; Truelsen, T.; et al. Global and regional burden of stroke during 1990-2010: Findings from the global burden of disease study 2010. Lancet 2014, 383, 245-255.

2. Lozano, R.; Naghavi, M.; Foreman, K.; Lim, S.; Shibuya, K.; Aboyans, V.; Abraham, J.; Adair, T.; Aggarwal, R.; Ahn, S.Y.; et al. Global and regional mortality from 235 causes of death for 20 age groups in 1990 and 2010: A systematic analysis for the global burden of disease study 2010. Lancet 2012, 380, 2095-2128.

3. Li, D.D.; Shao, Z.H.; Vanden Hoek, T.L.; Brorson, J.R. Reperfusion accelerates acute neuronal death induced by simulated ischemia. Exp. Neurol. 2007, 206, 280-287. 
4. Jung, J.E.; Kim, G.S.; Chen, H.; Maier, C.M.; Narasimhan, P.; Song, Y.S.; Niizuma, K.; Katsu, M.; Okami, N.; Yoshioka, H.; et al. Reperfusion and neurovascular dysfunction in stroke: From basic mechanisms to potential strategies for neuroprotection. Mol. Neurobiol. 2010, 41, 172-179.

5. Kristia, T.; Siesjo, B.K. Calcium in ischemic cell death. Stroke 1998, 29, 705-718.

6. Saito, A.; Maier, C.M.; Narasimhan, P.; Nishi, T.; Song, Y.S.; Yu, F.; Liu, J.; Lee, Y.-S.; Nito, C.; Kamada, H.; et al. Oxidative stress and neuronal death/survival signaling in cerebral ischemia. Mol. Neurobiol. 2005, 31, 105-116.

7. Vercesi, A.E.; Kowaltowski, A.J.; Oliveira, H.C.F.; Castilho, R.F. Mitochondrial $\mathrm{Ca}^{2+}$ transport, permeability transition and oxidative stress in cell death: Implications in cardiotoxicity, neurodegeneration and dyslipidemias. Front. Biosci. 2006, 11, 2554-2564.

8. Shi, H.L.; Liu, K.J. Cerebral tissue oxygenation and oxidative brain injury during ischemia and reperfusion. Front. Biosci. 2007, 12, 1318-1328.

9. Racay, P.; Tatarkova, Z.; Chomova, M.; Hatok, J.; Kaplan, P.; Dobrota, D. Mitochondrial calcium transport and mitochondrial dysfunction after global brain ischemia in rat hippocampus. Neurochem. Res. 2009, 34, 1469-1478.

10. Kasahara, A.; Scorrano, L. Mitochondria: From cell death executioners to regulators of cell differentiation. Trends Cell Biol. 2014, 24, 761-770.

11. Gulati, P.; Muthuraman, A.; Jaggi, A.S.; Singh, N. Neuroprotective effect of gadolinium: A stretch-activated calcium channel blocker in mouse model of ischemia-reperfusion injury. Naunyn-Schmiedeberg's Arch. Pharmacol. 2013, 386, 255-264.

12. McBride, H.M.; Neuspiel, M.; Wasiak, S. Mitochondria: More than just a powerhouse. Curr. Biol. CB 2006, 16, R551-R560.

13. Monteiro, P.; Oliveira, P.J.; Gonçalves, L.; Providência, L.A. Mitochondria: Role in ischemia,reperfusion and cell death. Rev. Port. Cardiol. 2003, 22, 233-254.

14. Thompson, J.W.; Narayanan, S.V.; Koronowski, K.B.; Morris-Blanco, K.; Dave, K.R.; Perez-Pinzon, M.A. Signaling pathways leading to ischemic mitochondrial neuroprotection. J. Bioenerg. Biomembr. 2015, 47, 101-110.

15. Granger, D.L.; Granger, D.N. Pathophysiology of ischaemia-reperfusion injury. J. Pathol. 2000, 190, 255-266.

16. Cottrill, K.A.; Chan, S.Y.; Loscalzo, J. Hypoxamirs and mitochondrial metabolism. Antioxid. Redox Signal. 2014, 21, 1189-1201.

17. Christian, P.; Su, Q. MicroRNA regulation of mitochondrial and ER stress signaling pathways: Implications for lipoprotein metabolism in metabolic syndrome. Am. J. Physiol. Endocrinol. Metab. 2014, 307, E729-E737.

18. Sripada, L.; Tomar, D.; Singh, R. Mitochondria: One of the destinations of miRNAs. Mitochondrion 2012, 12, 593-599.

19. Duarte, F.V.; Palmeira, C.M.; Rolo, A.P. The role of microRNAs in mitochondria: Small players acting wide. Genes 2014, 5, 865-886.

20. Fernández-Silva, P.; Enriquez, J.A.; Montoya, J. Replication and transcription of mammalian mitochondrial DNA. Exp. Physiol. 2003, 88, 41-55. 
21. Li, P.F.; Jiao, J.Q.; Gao, G.F.; Prabhakar, B.S. Control of mitochondrial activity by miRNAs. J. Cell. Biochem. 2012, 113, 1104-1110.

22. Kato, M.; Castro, N.E.; Natarajan, R. MicroRNAs: Potential mediators and biomarkers of diabetic complications. Free Radic. Biol. Med. 2013, 64, 85-94.

23. Fernandes, T.; Baraúna, V.G.; Negrão, C.E.; Phillips, M.I.; Oliveira, E.M. Aerobic exercise training promotes physiological cardiac remodeling involving a set of microRNAs. Am. J. Physiol. Heart Circ. Physiol. 2015, 309, H543-H552.

24. Mattson, M.P.; Gleichmann, M.; Cheng, A. Mitochondria in neuroplasticity and neurological disorders. Neuron 2008, 60, 748-766.

25. Ouyang, Y.B.; Stary, C.M.; White, R.E.; Giffard, R.G. The use of microRNAs to modulate redox and immune response to stroke. Antioxid. Redox Signal. 2015, 22, 187-202.

26. Ouyang, Y.-B. MicroRNAs: Innovative targets for cerebral ischemia and stroke. Curr. Drug Targets 2013, 14, 90-101.

27. Di, Y.; Lei, Y.; Yu, F.; Changfeng, F.; Song, W.; Xuming, M. MicroRNAs expression and function in cerebral ischemia reperfusion injury. J. Mol. Neurosci. 2014, 53, 242-250.

28. Jeyaseelan, K.; Lim, K.Y.; Armugam, A. MicroRNA expression in the blood and brain of rats subjected to transient focal ischemia by middle cerebral artery occlusion. Stroke 2008, 39, 959-966.

29. Scheibye-Knudsen, M.; Fang, E.F.; Croteau, D.L.; Wilson, D.M., III; Bohr, V.A. Protecting the mitochondrial powerhouse. Trends Cell Biol. 2015, 25, 158-170.

30. Brookes, P.S.; Yoon, Y.; Robotham, J.L.; Anders, M.W.; Sheu, S.-S. Calcium, ATP, and ROS: A mitochondrial love-hate triangle. Am. J. Physiol. Cell Physiol. 2004, 287, C817-C833.

31. Murphy, M.P. How mitochondria produce reactive oxygen species. Biochem. J. 2009, 417, 1-13.

32. Acin-Perez, R.; Hoyos, B.; Gong, J.L.; Vinogradov, V.; Fischman, D.A.; Leitges, M.; Borhan, B.; Starkov, A.; Manfredi, G.; Hammerling, U. Regulation of intermediary metabolism by the pkc delta signalosome in mitochondria. FASEB J. 2010, 24, 5033-5042.

33. Lee, H.-L.; Chen, C.-L.; Yeh, S.T.; Zweier, J.L.; Chen, Y.-R. Biphasic modulation of the mitochondrial electron transport chain in myocardial ischemia and reperfusion. Am. J. Physiol. Heart Circ. Physiol. 2012, 302, H1410-H1422.

34. Chen, Q.; Vazquez, E.J.; Moghaddas, S.; Hoppel, C.L.; Lesnefsky, E.J. Production of reactive oxygen species by mitochondria: Central role of complex III. J. Biol. Chem. 2003, 278, 36027-36031.

35. Wang, Q.; Sun, A.Y.; Simonyi, A.; Kalogeris, T.J.; Miller, D.K.; Sun, G.Y.; Korthuis, R.J. Ethanol preconditioning protects against ischemia/reperfusion-induced brain damage: Role of nadph oxidase-derived ros. Free Radic. Biol. Med. 2007, 43, 1048-1060.

36. Suh, S.W.; Shin, B.S.; Ma, H.L.; van Hoecke, M.; Brennan, A.M.; Yenari, M.A.; Swanson, R.A. Glucose and nadph oxidase drive neuronal superoxide formation in stroke. Ann. Neurol. 2008, 64, 654-663.

37. Dikalov, S. Cross talk between mitochondria and nadph oxidases. Free Radic. Biol. Med. 2011, $51,1289-1301$. 
38. Graham, K.A.; Kulawiec, M.; Owens, K.M.; Li, X.; Desouki, M.M.; Chandra, D.; Singh, K.K. NADPH oxidase 4 is an oncoprotein localized to mitochondria. Cancer Biol. Ther. 2014, 10, 223-231.

39. Kalogeris, T.; Bao, Y.; Korthuis, R.J. Mitochondrial reactive oxygen species: A double edged sword in ischemia/reperfusion vs preconditioning. Redox Biol. 2014, 2, 702-714.

40. Miyazawa, M.; Tsuji, Y. Evidence for a novel antioxidant function and isoform-specific regulation of the human p66Shc gene. Mol. Biol. Cell 2014, 25, 2116-2127.

41. Kowaltowski, A.J.; de Souza-Pinto, N.C.; Castilho, R.F.; Vercesi, A.E. Mitochondria and reactive oxygen species. Free Radic. Biol. Med. 2009, 47, 333-343.

42. Jezek, P.; Hlavata, L. Mitochondria in homeostasis of reactive oxygen species in cell, tissues, and organism. Int. J. Biochem. Cell Biol. 2005, 37, 2478-2503.

43. Circu, M.L.; Aw, T.Y. Reactive oxygen species, cellular redox systems, and apoptosis. Free Radic. Biol. Med. 2010, 48, 749-762.

44. Chen, H.; Yoshioka, H.; Kim, G.S.; Jung, J.E.; Okami, N.; Sakata, H.; Maier, C.M.; Narasimhan, P.; Goeders, C.E.; Chan, P.H. Oxidative stress in ischemic brain damage: Mechanisms of cell death and potential molecular targets for neuroprotection. Antioxid. Redox Signal. 2011, 14, 1505-1517.

45. Manzanero, S.; Santro, T.; Arumugam, T.V. Neuronal oxidative stress in acute ischemic stroke: Sources and contribution to cell injury. Neurochem. Int. 2013, 62, 712-718.

46. Sanderson, T.H.; Reynolds, C.A.; Kumar, R.; Przyklenk, K.; Huttemann, M. Molecular mechanisms of ischemia-reperfusion injury in brain: Pivotal role of the mitochondrial membrane potential in reactive oxygen species generation. Mol. Neurobiol. 2013, 47, 9-23.

47. Starkov, A.A.; Fiskum, G. Regulation of brain mitochondrial $\mathrm{H}_{2} \mathrm{O}_{2}$ production by membrane potential and NAD(P)H redox state. J. Neurochem. 2003, 86, 1101-1107.

48. Trenker, M.; Malli, R.; Fertschai, I.; Levak-Frank, S.; Graier, W.F. Uncoupling proteins 2 and 3 are fundamental for mitochondrial $\mathrm{Ca}^{2+}$ uniport. Nat. Cell Biol. 2007, 9, 445-452.

49. Dong, H.; Wang, S.; Zhang, Z.; Yu, A.; Liu, Z. The effect of mitochondrial calcium uniporter opener spermine on diazoxide against focal cerebral ischemia-Reperfusion injury in rats. J. Stroke Cerebrovasc. Dis. 2014, 23, 303-309.

50. Chinopoulos, C.; Adam-Vizi, V. Calcium, mitochondria and oxidative stress in neuronal pathology. Novel aspects of an enduring theme. FEBS J. 2006, 273, 433-450.

51. Halestrap, A.P.; Richardson, A.P. The mitochondrial permeability transition: A current perspective on its identity and role in ischaemia/reperfusion injury. J. Mol. Cell. Cardiol. 2015, 78, 129-141.

52. Yadava, N.; Nicholls, D.G. Spare respiratory capacity rather than oxidative stress regulates glutamate excitotoxicity after partial respiratory inhibition of mitochondrial complex I with rotenone. J. Neurosci. 2007, 27, 7310-7317.

53. Schagger, H.; Pfeiffer, K. The ratio of oxidative phosphorylation complexes I-V in bovine heart mitochondria and the composition of respiratory chain supercomplexes. J. Biol. Chem. 2001, 276, 37861-37867.

54. Sims, N.R.; Anderson, M.F. Mitochondrial contributions to tissue damage in stroke. Neurochem. Int. 2002, 40, 511-526. 
55. Folbergrova, J.; Zhao, Q.; Katsura, K.-I.; Siesjo, B.K. N-tert-butyl- $\alpha$-phenylnitrone improves recovery of brain energy state in rats following transient focal ischemia. Proc. Natl. Acad. Sci. USA 1995, 92, 5057-5061.

56. Haberg, A.; Qu, H.; Hjelstuen, M.H.; Sonnewald, U. Effect of the pyrrolopyrimidine lipid peroxidation inhibitor U-101033E on neuronal and astrocytic metabolism and infarct volume in rats with transient middle cerebral artery occlusion. Neurochem. Int. 2007, 50, 932-940.

57. Thoren, A.E.; Helps, S.C.; Nilsson, M.; Sims, N.R. The metabolism of ${ }^{14}$ C-glucose by neurons and astrocytes in brain subregions following focal cerebral ischemia in rats. J. Neurochem. 2006, 97, 968-978.

58. Yang, C.; Ko, B.; Hensley, C.T.; Jiang, L.; Wasti, A.T.; Kim, J.; Sudderth, J.; Calvaruso, M.A.; Lumata, L.; Mitsche, M.; et al. Glutamine oxidation maintains the TCA cycle and cell survival during impaired mitochondrial pyruvate transport. Mol. Cell 2014, 56, 414-424.

59. Belayev, L.; Zhao, W.Z.; Busto, R.; Ginsberg, M.D. Transient middle cerebral artery occlusion by intraluminal suture 1. Three-dimensional autoradiographic image-analysis of local cerebral glucose metabolism-blood flow interrelationships during ischemia and early recirculation. J. Cereb. Blood Flow Metab. 1997, 17, 1266-1280.

60. Sims, N.R.; Muyderman, H. Mitochondria, oxidative metabolism and cell death in stroke. Biochim. Biophys. Acta 2010, 1802, 80-91.

61. Green, D.R. Apoptotic pathways: The roads to ruin. Cell Death Differ. 1998, 94, 695-698.

62. Huttemann, M.; Pecina, P.; Rainbolt, M.; Sanderson, T.H.; Kagan, V.E.; Samavati, L.; Doan, J.W.; Lee, I. The multiple functions of cytochrome $\mathrm{c}$ and their regulation in life and death decisions of the mammalian cell: From respiration to apoptosis. Mitochondrion 2011, 11, 369-381.

63. Li, P.; Nijhawan, D.; Budihardjo, I.; Srinivasula, S.M.; Ahmad, M.; Alnemri, E.S.; Wang, X. Cytochrome $\mathrm{c}$ and dATP-dependent formation of Apaf-1/Caspase-9 complex initiates an apoptotic protease cascade. Cell 1997, 91, 479-489.

64. Guido, K.; John, R. Mitochondrial control of cell death. Nature 2000, 6, 513-519.

65. Garrido, C.; Galluzzi, L.; Brunet, M.; Puig, P.E.; Didelot, C.; Kroemer, G. Mechanisms of cytochrome c release from mitochondria. Cell Death Differ. 2006, 13, 1423-1433.

66. Ripple, M.O.; Abajian, M.; Springett, R. Cytochrome c is rapidly reduced in the cytosol after mitochondrial outer membrane permeabilization. Apoptosis Int. J. Programmed. Cell Death 2010, 15, 563-573.

67. Youle, R.J.; Strasser, A. The BCL-2 protein family: Opposing activities that mediate cell death. Nat. Rev. Mol. Cell Biol. 2008, 9, 47-59.

68. Oda, E.; Ohki, R.; Murasawa, H.; Nemoto, J.; Shibue, T.; Yamashita, T.; Tokino, T.; Taniguchi, T.; Tanaka, N. Noxa, a BH3-onty member of the BCL-2 family and candidate mediator of p53-induced apoptosis. Science 2000, 288, 1053-1058.

69. Kuwana, T.; Bouchier-Hayes, L.; Chipuk, J.E.; Bonzon, C.; Sullivan, B.A.; Green, D.R.; Newmeyer, D.D. BH3 domains of BH3-only proteins differentially regulate Bax-mediated mitochondrial membrane permeabilization both directly and indirectly. Mol. Cell 2005, 17, $525-535$. 
70. Hardwick, J.M.; Chen, Y.B.; Jonas, E.A. Multipolar functions of BCL-2 proteins link energetics to apoptosis. Trends Cell Biol. 2012, 22, 318-328.

71. Goldstein, J.C.; Munoz-Pinedo, C.; Ricci, J.E.; Adams, S.R.; Kelekar, A.; Schuler, M.; Tsien, R.Y.; Green, D.R. Cytochrome c is released in a single step during apoptosis. Cell Death Differ. 2005, $12,453-462$.

72. Kroemer, G.; Dallaporta, B. The mitochondrial death/life regulator in apoptosis and necrosis. Annu. Rev. Physiol. 1998, 60, 619-642.

73. Sinha, K.; Sil, P.C.; Das, J.; Pal, P.B. Oxidative stress: The mitochondria-dependent and mitochondria-independent pathways of apoptosis. Arch. Toxicol. 2013, 97, 1157-1180.

74. Yoshida, H.; Kong, Y.Y.; Yoshida, R.; Elia, A.J.; Hakem, A.; Hakem, R.; Penninger, J.M.; Mak, T.W. Apaf1 is required for mitochondrial pathways of apoptosis and brain development. Cell 1998, 94, 739-750.

75. Nakka, V.P.; Gusain, A.; Mehta, S.L.; Raghubir, R. Molecular mechanisms of apoptosis in cerebral ischemia: Multiple neuroprotective opportunities. Mol. Neurobiol. 2008, 37, 7-38.

76. Blomgren, K.; Zhu, C.; Wang, X.; Karlsson, J.O.; Leverin, A.L.; Bahr, B.A.; Mallard, C.; Hagberg, H. Synergistic activation of caspase-3 by m-calpain after neonatal hypoxia-ischemia: A mechanism of "pathological apoptosis"? J. Biol. Chem. 2001, 276, 10191-10198.

77. Filipowicz, W.; Bhattacharyya, S.N.; Sonenberg, N. Mechanisms of post-transcriptional regulation by microRNAs: Are the answers in sight? Nat. Rev. Genet. 2008, 9, 102-114.

78. Ambros, V. The functions of animal microRNAs. Nature 2004, 431, 350-354.

79. Lee, Y.; Ahn, C.; Han, J.; Choi, H.; Kim, J.; Yim, J.; Lee, J.; Provost, P.; Rådmark, O.; Kim, S.K.V.N. The nuclear RNase III Drosha initiates microRNA processing. Nature 2003, 425, 415-419.

80. Lee, Y.; Kim, M.; Han, J.; Yeom, K.-H.; Lee, S.; Baek, S.H.; Kim, V.N. MicroRNA genes are transcribed by RNA polymerase II. EMBO J. 2004, 23, 4051-4060.

81. Kawamata, T.; Tomari, Y. Making risc. Trends Biochem. Sci. 2010, 35, 368-376.

82. Okamura, K.; Phillips, M.D.; Tyler, D.M.; Duan, H.; Chou, Y.T.; Lai, E.C. The regulatory activity of microRNA* species has substantial influence on microRNA and 3' UTR evolution. Nat. Struct. Mol. Biol. 2008, 15, 354-363.

83. Almeida, M.I.; Reis, R.M.; Calin, G.A. MicroRNA history: Discovery, recent applications, and next frontiers. Mutat. Res. 2011, 717, 1-8.

84. Varallyay, E.; Burgyan, J.; Havelda, Z. MicroRNA detection by northern blotting using locked nucleic acid probes. Nat. Protocols 2008, 3, 190-196.

85. Friedlander, M.R.; Chen, W.; Adamidi, C.; Maaskola, J.; Einspanier, R.; Knespel, S.; Rajewsky, N. Discovering microRNAs from deep sequencing data using mirdeep. Nat. Biotechnol. 2008, 26, 407-415.

86. Garofalo, M.; Condorelli, G.L.; Croce, C.M.; Condorelli, G. MicroRNAs as regulators of death receptors signaling. Cell Death Differ. 2010, 17, 200-208.

87. Graves, P.; Zeng, Y. Biogenesis of mammalian microRNAs: A global view. Genom. Proteom. Bioinform. 2012, 10, 239-245.

88. Smirnova, L.; Grafe, A.; Seiler, A.; Schumacher, S.; Nitsch, R.; Wulczyn, F.G. Regulation of miRNA expression during neural cell specification. Eur. J. Neurosci. 2005, 21, 1469-1477. 
89. Lewis, B.P.; Burge, C.B.; Bartel, D.P. Conserved seed pairing, often flanked by adenosines, indicates that thousands of human genes are microRNA targets. Cell 2005, 120, 15-20.

90. Wulczyn, F.G.; Smirnova, L.; Rybak, A.; Brandt, C.; Kwidzinski, E.; Ninnemann, O.; Strehle, M.; Seiler, A.; Schumacher, S.; Nitsch, R. Post-transcriptional regulation of the let-7 microRNA during neural cell specification. FASEB J. 2007, 21, 415-426.

91. Tan, K.S.; Armugam, A.; Sepramaniam, S.; Lim, K.Y.; Dwi, K.; Setyowati; Wang, C.W.; Jeyaseelan, K. Expression profile of microRNAs in young stroke patients. PLoS ONE 2009, 4, e7689.

92. Kren, B.T.; Wong, P.Y.P.; Sarver, A.; Zhang, X.; Zeng, Y.; Steer, C.J. MicroRNAs identified in highly purified liver-derived mitochondria may play a role in apoptosis. RNA Biol. 2009, 6, $65-72$.

93. Das, S.; Ferlito, M.; Kent, O.A.; Fox-Talbot, K.; Wang, R.; Liu, D.; Raghavachari, N.; Yang, Y.; Wheelan, S.J.; Murphy, E.; et al. Nuclear miRNA regulates the mitochondrial genome in the heart. Circ. Res. 2012, 110, 1596-1603.

94. Chen, Z.; Li, Y.; Zhang, H.; Huang, P.; Luthra, R. Hypoxia-regulated microRNA-210 modulates mitochondrial function and decreases ISCU and COX10 expression. Oncogene 2010, 29, 4362-4368.

95. Shi, Q.; Gibson, G.E. Up-regulation of the mitochondrial malate dehydrogenase by oxidative stress is mediated by miR-743a. J. Neurochem. 2011, 118, 440-448.

96. Venkataraman, S.; Alimova, I.; Fan, R.; Harris, P.; Foreman, N.; Vibhakar, R. MicroRNA 128a increases intracellular ROS level by targeting Bmi-1 and inhibits medulloblastoma cancer cell growth by promoting senescence. PLOS ONE 2010, 5, e10748.

97. Cha, M.J.; Jang, J.K.; Ham, O.; Song, B.W.; Lee, S.Y.; Lee, C.Y.; Park, J.H.; Lee, J.; Seo, H.H.; Choi, E.; et al. MicroRNA-145 suppresses ROS-induced $\mathrm{Ca}^{2+}$ overload of cardiomyocytes by targeting camkiidelta. Biochem. Biophysic. Res. Commun. 2013, 435, 720-726.

98. Wang, J.; Wu, M.; Wen, J.; Yang, K.; Li, M.; Zhan, X.; Feng, L.; Li, M.; Huang, X. MicroRNA-155 induction by Mycobacterium bovis BCG enhances ROS production through targeting SHIP1. Mol. Immunol. 2014, 62, 29-36.

99. Kahles, T.; Luedike, P.; Endres, M.; Galla, H.J.; Steinmetz, H.; Busse, R.; Neumann-Haefelin, T.; Brandes, R.P. NADPH oxidase plays a central role in blood-brain barrier damage in experimental stroke. Stroke 2007, 38, 3000-3006.

100. Donadelli, M.; Dando, I.; Fiorini, C.; Palmieri, M. Regulation of miR-23b expression and its dual role on ROS production and tumour development. Cancer Lett. 2014, 349, 107-113.

101. Varga, Z.V.; Kupai, K.; Szucs, G.; Gaspar, R.; Paloczi, J.; Farago, N.; Zvara, A.; Puskas, L.G.; Razga, Z.; Tiszlavicz, L.; et al. MicroRNA-25-dependent up-regulation of NADPH oxidase 4 (NOX4) mediates hypercholesterolemia-induced oxidative/nitrative stress and subsequent dysfunction in the heart. J. Mol. Cell. Cardiol. 2013, 62, 111-121.

102. Li, S.Z.; Hu, Y.Y.; Zhao, J.; Zhao, Y.B.; Sun, J.D.; Yang, Y.F.; Ji, C.C.; Liu, Z.B.; Cao, W.D.; Qu, Y.; et al. MicroRNA-34a induces apoptosis in the human glioma cell line, A172, through enhanced ros production and NOX2 expression. Biochem. Biophys. Res.Commun. 2014, 444, $6-12$. 
103. Sugawara, T.; Chan, P.H. Reactive oxygen radicals and pathogenesis of neuronal death after cerebral ischemia. Antioxid. Redox Signal. 2003, 5, 597-607.

104. Xu, Y.; Fang, F.; Zhang, J.; Josson, S.; Clair, W.H.S.; Clair, D.K.S. miR-17* suppresses tumorigenicity of prostate cancer by inhibiting mitochondrial antioxidant enzymes. PLoS ONE 2010, 5, 1-7.

105. Bai, X.Y.; Ma, Y.; Ding, R.; Fu, B.; Shi, S.; Chen, X.M. miR-335 and miR-34a promote renal senescence by suppressing mitochondrial antioxidative enzymes. J. Am. Soc.Nephrol. JASN 2011, $22,1252-1261$.

106. Wang, L.; Huang, H.; Fan, Y.; Kong, B.; Hu, H.; Hu, K.; Guo, J.; Mei, Y.; Liu, W.L. Effects of downregulation of microRNA-181a on $\mathrm{H}_{2} \mathrm{O}_{2}$-induced $\mathrm{H} 9 \mathrm{c} 2$ cell apoptosis via the mitochondrial apoptotic pathway. Oxidative Med. Cell. Longev. 2014, 2014, doi:10.1155/2014/960362.

107. Zhang, X.; Ng, W.L.; Wang, P.; Tian, L.; Werner, E.; Wang, H.; Doetsch, P.; Wang, Y. MicroRNA-21 modulates the levels of reactive oxygen species by targeting SOD3 and TNFa. Cancer Res. 2012, 72, 4707-4713.

108. Wei, C.; Li, L.; Kim, I.K.; Sun, P.; Gupta, S. NF-אB mediated miR-21 regulation in cardiomyocytes apoptosis under oxidative stress. Free Radic. Res. 2014, 48, 282-291.

109. Haque, R.; Chun, E.; Howell, J.C.; Sengupta, T.; Chen, D.; Kim, H. MicroRNA-30b-mediated regulation of catalase expression in human ARPE-19 cells. PLOS ONE 2012, 7, e42542.

110. Im, Y.B.; Jee, M.K.; Jung, J.S.; Choi, J.I.; Jang, J.H.; Kang, S.K. miR23b ameliorates neuropathic pain in spinal cord by silencing NADPH oxidase 4. Antioxid. Redox Signal. 2012, 16, 1046-1060.

111. Chen, P.H.; Shih, C.M.; Chang, W.C.; Cheng, C.H.; Lin, C.W.; Ho, K.H.; Su, P.C.; Chen, K.C. MicroRNA-302b-inhibited E2F3 transcription factor is related to all trans retinoic acid-induced glioma cell apoptosis. J. Neurochem. 2014, 131, 731-742.

112. Gao, P.; Tchernyshyov, I.; Chang, T.C.; Lee, Y.S.; Kita, K.; Ochi, T.; Zeller, K.I.; de Marzo, A.M.; Van Eyk, J.E.; Mendell, J.T.; et al. c-Myc suppression of miR-23a/b enhances mitochondrial glutaminase expression and glutamine metabolism. Nature 2009, 458, 762-765.

113. Mallat, Y.; Tritsch, E.; Ladouce, R.; Winter, D.L.; Friguet, B.; Li, Z.; Mericskay, M. Proteome modulation in H9c2 cardiac cells by microRNAs miR-378 and miR-378*. Mol. Cell. Proteom. MCP 2014, 13, 18-29.

114. Eichner, L.J.; Perry, M.C.; Dufour, C.R.; Bertos, N.; Park, M.; St-Pierre, J.; Giguere, V. miR-378* mediates metabolic shift in breast cancer cells via the PGC-1 $\beta /$ ERR $\gamma$ transcriptional pathway. Cell Metab. 2010, 12, 352-361.

115. Sun, L.L.; Jiang, B.G.; Li, W.T.; Zou, J.J.; Shi, Y.Q.; Liu, Z.M. MicroRNA-15a positively regulates insulin synthesis by inhibiting uncoupling protein-2 expression. Diabetes Res. Clin. Pract. 2011, 91, 94-100.

116. Nishi, H.; Ono, K.; Iwanaga, Y.; Horie, T.; Nagao, K.; Takemura, G.; Kinoshita, M.; Kuwabara, Y.; Mori, R.T.; Hasegawa, K.; et al. MicroRNA-15b modulates cellular ATP levels and degenerates mitochondria via Arl2 in neonatal rat cardiac myocytes. J. Biol. Chem. 2010, 285, 4920-4930.

117. Aschrafi, A.; Schwechter, A.D.; Mameza, M.G.; Natera-Naranjo, O.; Gioio, A.E.; Kaplan, B.B. MicroRNA-338 regulates local cytochrome c oxidase IV mRNA levels and oxidative phosphorylation in the axons of sympathetic neurons. J. Neurosci.2008, 28, 12581-12590. 
118. Baseler, W.A.; Thapa, D.; Jagannathan, R.; Dabkowski, E.R.; Croston, T.L.; Hollander, J.M. miR-141 as a regulator of the mitochondrial phosphate carrier (Slc25a3) in the type 1 diabetic heart. Am. J. Physiol. Cell Physiol. 2012, 303, C1244-C1251.

119. Li, B.; Zhang, Z.; Zhang, H.; Quan, K.; Lu, Y.; Cai, D.; Ning, G. Aberrant miR199a-5p/caveolin1/PPAR $\alpha$ axis in hepatic steatosis. J. Mol. Endocrinol. 2014, 53, 393-403.

120. Aoi, W.; Naito, Y.; Mizushima, K.; Takanami, Y.; Kawai, Y. The microRNA miR-696 regulates PGC-1 in mouse skeletal muscle in response to physical activity. Am. J. Physiol. Endocrinol. Metab. 2010, 298, E799-E806.

121. Liu, A.M.; Xu3, Z.; Shek, F.H.; Wong, K.-F.; Lee, N.P.; Poon, R.T.; Chen, J.; Luk, J.M. miR-122 targets pyruvate kinase M2 and affects metabolism of hepatocellular carcinoma. PLOS ONE 2014, 9, 1-9.

122. Zhang, C.; Zhang, J.; Zhang, A.; Wang, Y.; Han, L.; You, Y.; Pu, P.; Kang, C. Puma is a novel target of miR-221/222 in human epithelial cancers. Int. J. Oncol. 2010, 37, 1621-1626.

123. Huang, W.; Liu, X.; Cao, J.; Meng, F.; Li, M.; Chen, B.; Zhang, J. miR-134 regulates ischemia/reperfusion injury-induced neuronal cell death by regulating creb signaling. J. Mol. Neurosci. 2015, 55, 821-829.

124. Ouyang, Y.B.; Xu, L.; Lu, Y.; Sun, X.; Yue, S.; Xiong, X.X.; Giffard, R.G. Astrocyte-enriched miR-29a targets puma and reduces neuronal vulnerability to forebrain ischemia. Glia 2013, 61, 1784-1794.

125. Li, R.; Yan, G.; Li, Q.; Sun, H.; Hu, Y.; Sun, J.; Xu, B. MicroRNA-145 protects cardiomyocytes against hydrogen peroxide $\left(\mathrm{H}_{2} \mathrm{O}_{2}\right)$-induced apoptosis through targeting the mitochondria apoptotic pathway. PLoS ONE 2012, 7, e44907.

126. Liang, N.; Wang, P.; Wang, S.; Li, S.; Li, Y.; Wang, J.; Wang, M. Role of mitochondrial calcium uniporter in regulating mitochondrial fission in the cerebral cortexes of living rats. J. Neural Transm. 2014, 121, 593-600.

127. Ouyang, Y.B.; Lu, Y.; Yue, S.; Xu, L.J.; Xiong, X.X.; White, R.E.; Sun, X.; Giffard, R.G. miR-181 regulates GRP78 and influences outcome from cerebral ischemia in vitro and in vivo. Neurobiol. Dis. 2012, 45, 555-563.

128. Yadav, S.; Pandey, A.; Shukla, A.; Talwelkar, S.S.; Kumar, A.; Pant, A.B.; Parmar, D. miR-497 and miR-302b regulate ethanol-induced neuronal cell death through BCL2 protein and cyclin D2. J. Biol. Chem. 2011, 286, 37347-37357.

129. Shi, L.; Chen, J.; Yang, J.; Pan, T.; Zhang, S.; Wang, Z. miR-21 protected human glioblastoma U87MG cells from chemotherapeutic drug temozolomide induced apoptosis by decreasing Bax/Bcl-2 ratio and caspase-3 activity. Brain Res. 2010, 1352, 255-264.

130. Huang, L.G.; Li, J.P.; Pang, X.M.; Chen, C.Y.; Xiang, H.Y.; Feng, L.B.; Su, S.Y.; Li, S.H.; Zhang, L.; Liu, J.L. MicroRNA-29c correlates with neuroprotection induced by FNS by targeting both Birc2 and Bak1 in rat brain after stroke. CNS Neurosci. Ther. 2015, 21, 496-503.

131. Chad Siegel, J.L., Fudong Liu, Sharon E. Benashski, and Louise D. McCullough. miR-23a regulation of X-linked inhibitor of apoptosis(XIAP) contributes to sex differences in the response to cerebral ischemia. PNAS 2011, 108, 11662-11667. 
132. Shang, J.; Yang, F.; Wang, Y.; Wang, Y.; Xue, G.; Mei, Q.; Wang, F.; Sun, S. MicroRNA-23a antisense enhances 5-fluorouracil chemosensitivity through Apaf-1/Caspase-9 apoptotic pathway in colorectal cancer cells. J. Cell. Biochem. 2014, 115, 772-784.

133. Wang, J.X.; Jiao, J.Q.; Li, Q.; Long, B.; Wang, K.; Liu, J.P.; Li, Y.R.; Li, P.F. miR-499 regulates mitochondrial dynamics by targeting calcineurin and dynamin-related protein-1. Nat. Med. 2011, $17,71-78$.

134. Wang, L.; Li, X.; Zhou, Y.; Shi, H.; Xu, C.; He, H.; Wang, S.; Xiong, X.; Zhang, Y.; $\mathrm{Du}, \mathrm{Z}$; et al. Downregulation of miR-133 via MAPK/ERK signaling pathway involved in nicotine-induced cardiomyocyte apoptosis. Naunyn-Schmiedeberg's Arch. Pharmacol. 2014, 387, 197-206.

135. Zhu, F.; Liu, J.L.; Li, J.P.; Xiao, F.; Zhang, Z.X.; Zhang, L. MicroRNA-124 (miR-124) regulates $\mathrm{Ku} 70$ expression and is correlated with neuronal death induced by ischemia/reperfusion. J. Mol. Neurosci. 2014, 52, 148-155.

136. Long, B.; Wang, K.; Li, N.; Murtaza, I.; Xiao, J.Y.; Fan, Y.Y.; Liu, C.Y.; Li, W.H.; Cheng, Z.; Li, P. miR-761 regulates the mitochondrial network by targeting mitochondrial fission factor. Free Radic. Biol. Med. 2013, 65, 371-379.

137. Aurora, A.B.; Mahmoud, A.I.; Luo, X.; Johnson, B.A.; Rooij, E.v.; Matsuzaki, S.; Humphries, K.M.; Hill, J.A.; Rhonda Bassel-Duby; Sadek, H.A.; et al. MicroRNA-214 protects the mouse heart from ischemic injury by controlling $\mathrm{Ca}^{2+}$ overload and cell death. J. Clin. Investig. 2014, 122, 1222-1232.

138. Sacco, J.; Adeli, K. MicroRNAs: Emerging roles in lipid and lipoprotein metabolism. Curr. Opin. Lipidol. 2012, 23, 220-225.

139. Chang, W.; Lee, C.Y.; Park, J.H.; Park, M.S.; Maeng, L.S.; Yoon, C.S.; Lee, M.Y.; Hwang, K.C.; Chung, Y.A. Survival of hypoxic human mesenchymal stem cells is enhanced by a positive feedback loop involving miR-210 and hypoxia-inducible factor 1. J. Vet. Sci. 2013, 14, 69-76.

140. Griffin, S.; Clark, J.B.; Canevari, L. Astrocyte-neurone communication following oxygen-glucose deprivation. J. Neurochem. 2005, 95, 1015-1022.

141. Tanaka, H.; Sasayama, T.; Tanaka, K.; Nakamizo, S.; Nishihara, M.; Mizukawa, K.; Kohta, M.; Koyama, J.; Miyake, S.; Taniguchi, M.; et al. MicroRNA-183 upregulates HIF-1 $\alpha$ by targeting isocitrate dehydrogenase 2 (IDH2) in glioma cells. J. Neurooncol. 2013, 111, 273-283.

142. Hwang, I.K.; Yoo, K.Y.; Kim, D.W.; Lee, C.H.; Choi, J.H.; Kwon, Y.G.; Kim, Y.M.; Choi, S.Y.; Won, M.H. Changes in the expression of mitochondrial peroxiredoxin and thioredoxin in neurons and glia and their protective effects in experimental cerebral ischemic damage. Free Radic. Biol. Med. 2010, 48, 1242-1251.

143. Cande, C.; Cohen, I.; Daugas, E.; Ravagnan, L.; Larochette, N.; Zamzami, N.; Kroemer, G. Apoptosis-inducing factor (AIF): A novel caspase-independent death effector released from mitochondria. Biochimie 2002, 84, 215-222.

144. Arnoult, D.; Gaume, B.; Karbowski, M.; Sharpe, J.C.; Cecconi, F.; Youle, R.J. Mitochondrial release of AIF and Endog requires caspase activation downstream of Bax/Bak-mediated permeabilization. Embo J. 2003, 22, 4385-4399.

145. Vousden, K.H. P53: Death star. Cell 2000, 103, 691-694. 
146. Vaseva, A.V.; Marchenko, N.D.; Ji, K.; Tsirka, S.E.; Holzmann, S.; Moll, U.M. P53 opens the mitochondrial permeability transition pore to trigger necrosis. Cell 2012, 149, 1536-1548.

147. Su, W.; Hopkins, S.; Nesser, N.K.; Sopher, B.; Silvestroni, A.; Ammanuel, S.; Jayadev, S.; Moller, T.; Weinstein, J.; Garden, G.A. The p53 transcription factor modulates microglia behavior through microRNA-dependent regulation of c-Maf. J. Immunol. 2014, 192, 358-366.

148. Forini, F.; Kusmic, C.; Nicolini, G.; Mariani, L.; Zucchi, R.; Matteucci, M.; Iervasi, G.; Pitto, L. Triiodothyronine prevents cardiac ischemia/reperfusion mitochondrial impairment and cell loss by regulating miR30a/p53 axis. Endocrinology 2014, 155, 4581-4590.

149. Roshan, R.; Shridhar, S.; Sarangdhar, M.A.; Banik, A.; Chawla, M.; Garg, M.; Singh, V.P.; Pillai, B. Brain-specific knockdown of miR-29 results in neuronal cell death and ataxia in mice. RNA-Publ. RNA Soc. 2014, 20, 1287-1297.

150. Jafarinejad-Farsangi, S.; Farazmand, A.; Mahmoudi, M.; Gharibdoost, F.; Karimizadeh, E.; Noorbakhsh, F.; Faridani, H.; Jamshidi, A.R. MicroRNA-29a induces apoptosis via increasing the Bax:BCL-2 ratio in dermal fibroblasts of patients with systemic sclerosis. Autoimmunity 2015, 48, 369-378.

151. Moon, J.M.; Xu, L.; Giffard, R.G. Inhibition of microRNA-181 reduces forebrain ischemia-induced neuronal loss. J. Cereb. Blood Flow Metab. 2013, 33, 1976-1982.

152. Yin, K.J.; Deng, Z.; Huang, H.; Hamblin, M.; Xie, C.; Zhang, J.; Chen, Y.E. miR-497 regulates neuronal death in mouse brain after transient focal cerebral ischemia. Neurobiol. Dis. 2010, 38, $17-26$.

153. Cho, S.-G.; Du, Q.; Huang, S.; Dong, Z. Drp1 dephosphorylation in ATP depletion-induced mitochondrial injury and tubular cell apoptosis. Am. J. Physiol. Ren. Physiol. 2010, 21, F199-F206.

154. Gladstone, D.J.; Black, S.E.; Hakim, A.M. Toward wisdom from failure: Lessons from neuroprotective stroke trials and new therapeutic directions. Stroke 2002, 33, 2123-2136.

155. Liu, C.; Peng, Z.; Zhang, N.; Yu, L.; Han, S.; Li, D.; Li, J. Identification of differentially expressed microRNAs and their PKC-isoform specific gene network prediction during hypoxic pre-conditioning and focal cerebral ischemia of mice. J. Neurochem. 2012, 120, 830-841.

156. Kalani, A.; Kamat, P.K.; Tyagi, S.C.; Tyagi, N. Synergy of homocysteine, microRNA, and epigenetics: A novel therapeutic approach for stroke. Mol. Neurobiol. 2013, 48, 157-168.

157. Kozomara, A.; Griffiths-Jones, S. miRBase: Integrating microRNA annotation and deep-sequencing data. Nucleic Acids Res. 2011, 39, D152-D157.

158. Hinske, L.C.; Galante, P.A.; Kuo, W.P.; Ohno-Machado, L. A potential role for intragenic miRNAs on their hosts' interactome. BMC Genom. 2010, 11, doi:10.1186/1471-2164-11-533.

159. Zisoulis, D.G.; Kai, Z.S.; Chang, R.K.; Pasquinelli, A.E. Autoregulation of microRNA biogenesis by let-7 and argonaute. Nature 2012, 486, 541-544.

160. Khraiwesh, B.; Arif, M.A.; Seumel, G.I.; Ossowski, S.; Weigel, D.; Reski, R.; Frank, W. Transcriptional control of gene expression by microRNAs. Cell 2010, 140, 111-122.

161. Li, Z.; Rana, T.M. Therapeutic targeting of microRNAs: Current status and future challenges. Nat. Rev. Drug Discov. 2014, 13, 622-638.

162. Xu, L.J.; Ouyang, Y.B.; Xiong, X.; Stary, C.M.; Giffard, R.G. Post-stroke treatment with miR-181 antagomir reduces injury and improves long-term behavioral recovery in mice after focal cerebral ischemia. Exp. Neurol. 2015, 264, 1-7. 
163. Peng, Z.; Li, J.; Li, Y.; Yang, X.; Feng, S.; Han, S.; Li, J. Downregulation of miR-181b in mouse brain following ischemic stroke induces neuroprotection against ischemic injury through targeting heat shock protein A5 and ubiquitin carboxyl-terminal hydrolase isozyme L1. J. Neurosci. Res. 2013, 91, 1349-1362.

164. Selvamani, A.; Sathyan, P.; Miranda, R.C.; Sohrabji, F. An antagomir to microRNA let7f promotes neuroprotection in an ischemic stroke model. PLOS ONE 2012, 7, e32662.

165. Liu, P.; Zhao, H.; Wang, R.; Wang, P.; Tao, Z.; Gao, L.; Yan, F.; Liu, X.; Yu, S.; Ji, X.; et al. MicroRNA-424 protects against focal cerebral ischemia and reperfusion injury in mice by suppressing oxidative stress. Stroke 2015, 46, 513-519.

166. Stary, C.M.; Xu, L.; Sun, X.; Ouyang, Y.-B.; White, R.E.; Leong, J.; Li, J.; Xiong, X.; Giffard, R.G. MicroRNA-200c contributes to injury from transient focal cerebral ischemia by targeting reelin. Stroke 2015, 46, 551-556.

(C) 2015 by the authors; licensee MDPI, Basel, Switzerland. This article is an open access article distributed under the terms and conditions of the Creative Commons Attribution license (http://creativecommons.org/licenses/by/4.0/). 